\title{
A Reconsideration of the Measurements with the O Ring Stack
}

\section{B. T. Cleveland and J. K. Rowley September 1996}

\begin{abstract}
The measurements that were made in the spring of this year of Rn entry to the 0 ring stack were interpreted as representing diffusion through the urethane o rings in STR-96-013 ('On Rn Diffusion through Urethane and Polypropylene', 4 March 1996). This interpretation was, however, not firmly established because the derived diffusion constant $D=2.8 \times 10 *(-7) \mathrm{cm} * * 2 / \mathrm{sec}$ was more than an order of magnitude larger than is expected for $R n$ in rubbers. This led to the alternative hypothesis that Rn was mainly entering the stack by leakage through a small hole, rather than by diffusion.
\end{abstract}

This note presents a calculation of diffusion from first principles and rederives the diffusion constant for the 0 ring stack measurements.

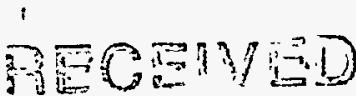

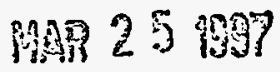

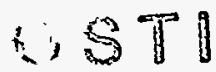
flow along the $x$-axis. The concentration $c(x, t)$ satisfies the diffusion equation

$$
\begin{aligned}
& \text { dc d d } \\
& --=D--C \text { - }-1 a m b d a * C \\
& d t \quad d x d x
\end{aligned}
$$

where lambda $=2.1 \times 10 * *(-6) / \mathrm{sec}$ is the $\mathrm{Rn}$ decay constant. In the steady state $\mathrm{dc} / \mathrm{dt}=0$ and

$$
\begin{aligned}
& \text { d d lambda } \\
& --c=\cdots=-c \\
& d x d x \quad D
\end{aligned}
$$

which has the general solution $C(x)=A \exp (k x)+B \exp (-k x)$ where $k=\operatorname{sqrt}($ lambda/D), with $A$ and $B$ constants that are set by applying boundary conditions.

In the case of diffusion through a membrane of thickness d that separates two volumes in which the $R n$ concentrations are $c 1$ and $C 2$, the boundary conditions are $c(x=0)=s C 1$ and $c(x=d)=S C 2$, where $S$ is the solubility of $R n$ in the membrane material. This leads to the general expression for the concentration

$$
c(x)=s-\operatorname{cl}\{\exp [k(d-x)]-\exp -[(k(d-x)]\}+c 2[\exp (k x)-\exp (-k x)]
$$

The flux $F$ of $R$, that emerges from the membrane at $x=d$ is

$$
\begin{aligned}
& F=-D-\begin{array}{l}
d C \\
d x
\end{array} \mid x=d \\
&=D S k-C 2[\exp (k d)+\exp (-k d)] \\
& 2 C 1-\exp (k d)-\exp (-k d)
\end{aligned}
$$

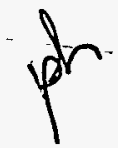

(5) 


\section{B. Application to the O Ring Stack}

After assembly, the $O$ ring stack was first evacuated and then left undisturbed for several days to establish equilibrium. Rn extractions were then made approximately every day and the number of inflowing $R n$ atoms was measured in a Lucas cell to be appx. 30 per hour or 1 every 120 seconds. In this mode of operation, $\mathrm{C} 2$ in eq. (2) is approximately zero, so this measured flux is equal to

$D S k 2 C 1 /[\exp (k d)-\exp (-k d)]=1 / 120 /($ Effective 0 ring area) (eq. 3 )

In first approximation (see STR-96-013) the 0 ring stack contains 21 polyurethane $O$ rings with $33 / 8$ inch $O D$ and 0.139 inch thickness. The groove depth and width were chosen (see drawing WPS-D-D-6102-02) to be 70 and 127f, resp., of the uncompressed thickness. With these dimensions, the compressed 0 ring just contacts the sides of the groove and the minimum distance through which Rn must diffuse to reach the interior of the stack is 57 of the uncompressed $O$ ring thickness, i.e. $2.0 \mathrm{~mm}$. The area of each 0 ring directly exposed to the outside air (and to the interior vacuum) was appx. $5.2 \mathrm{~cm} * 22$, or $110 \mathrm{~cm}^{\star * 2}$ for all rings. Assuming (1) the 0 ring stack approximates linear diffusion through the distance $d=0.2 \mathrm{~cm},(2)$ the concentration of $\mathrm{Rn}$ in the air outside the stack was $\mathrm{Cl}=3 \mathrm{pCi} /$ liter (equivalent to $53 \mathrm{Rn}$ atoms $/ \mathrm{cm} * \star 3$ ), and (3) the solubility of $R n$ in polyurethane is $S=.5 .6$, numerical solution of eq. (3) gives $D=6.3 \times 10(-8) \mathrm{cm}^{* * 2} / \mathrm{sec}$.

The diffusion constant of soft polyurethane given by M Wojcik ['Measurement of radon diffusion and solubility constants in membranes', Nucl. Ingtr. and Meth. B61, page 8 (1991)] is $4.1 \times 10(-8) \mathrm{cm} * * 2 / \mathrm{sec}$. Considering the possible variations in polyurethane composition, and the approximations used above, this value is in essential agreement with that determined with the 0 ring stack, thus adding further credence to the supposition that diffusion is the cause of Rn entry in the $O$ ring stack.

The primary differences between this analysis and that given in STR-96-013 are (1) the solubility constant $S$ was not included in the latter work and (2) the effective distance through which Rn must diffuse was taken here to be the minimum distance of 0 ring contact, rather than the uncompressed thickness of the 0 ring.

Acknowledgement. This research was carried out at Brookhaven National Laboratory under contract DE-ACO2-iECH00016 with the Department of Energy. 


\section{DISCLAIMER}

This report was prepared as an account of work sponsored by an agency of the United States Government. Neither the United States Government nor any agency thereof, nor any of their employees, make any warranty, express or implied, or assumes any legal liability or responsibility for the accuracy, completeness, or usefulness of any information, apparatus, product, or process disclosed, or represents that its use would not infringe privately owned rights. Reference herein to any specific commercial product, process, or service by trade name, trademark, manufacturer, or otherwise does not necessarily constitute or imply its endorsement, recommendation, or favoring by the United States Government or any agency thereof. The views and opinions of authors expressed herein do not necessarily state or reflect those of the United States Government or any agency thereof. 


\section{DISCLAMMER}

Portions of this document may be illegible in electronic image products. Images are produced from the best available original document. 